\title{
Barriers for Dentists in Treating Children with Autism Spectrum Disorders
}

\author{
Nidhi Taneja ${ }^{1}$, Mark D Litt²
}

\begin{abstract}
Aim: To investigate barriers in providing dental care for children with autism spectrum disorder (ASD) for the dentists.

Materials and methods: A survey outlining various barriers in treating children with ASD was administered to 109 general dentists. Potential barriers assessed in the survey included: Lack of practice guidelines to manage children with ASD, perceived disruptive behavior of ASD children, and lack of self-perceived competency or time in managing these patients.

Results: Seventy-four percent of the general dentists reported treating children with ASD. On average, they treated fewer than three children with ASD per month. The mean number of barriers endorsed by the dentists treating children with ASD was marginally more than those not treating ASD children, and not statistically significant $(t=-0.28 ; \mathrm{df}=107 ; p=0.78)$. Lack of practice guidelines for treating children with ASD was the most common barrier endorsed.

Conclusion: The most commonly endorsed barriers to provision of care perceived by general dentists were lack of guidelines for care, lack of sufficient reimbursement for management of ASD children, and difficulty in managing the behavior of ASD children. General dentists, who will be assuming more of the treatment for these children, will need to be better trained to manage the behavioral challenges of children with ASD.

Keywords: Access to care, Autism, Barriers, Dentist.

Journal of South Asian Association of Pediatric Dentistry (2020): 10.5005/jp-journals-10077-3055
\end{abstract}

\section{INTRODUCTION}

Autism spectrum disorder (ASD) is a neurodevelopmental disorder that affects many areas of life. ${ }^{1,2}$ Autism spectrum disorder may involve a number of problems in behavior and capacity that make them challenging for dentists to treat, including impairments in language, difficulty in social interactions, and tantrum behaviors. Manifestations of the disorder vary depending on the developmental level and age of the individual, thus different children will respond differently to dental interventions at different ages. $^{3}$

The recent increase in the prevalence of ASD in the United States ${ }^{4,5}$ means that dental practitioners will be seeing an increasing number of patients with ASD as well. Several studies have noted unmet dental needs in children with autism. ${ }^{6-8}$ This may be due to the complex medical and behavioral needs of children with ASD, making them a difficult population, on average, to treat in a private dental office. ${ }^{9}$ Barriers to dental care for children, specifically those with ASD, have been reported in the literature. ${ }^{8,10,11}$ Though many studies have been conducted from a caregiver's perspective, ${ }^{7,8,10-12}$ only a handful of them delve into the barriers to provide care to ASD children perceived by dentists. ${ }^{13,14}$

General dentists treat patients of all age groups, but the numbers of special needs patients they treat is limited. ${ }^{15,16}$ They are also the ones who treat children in their adolescent years through adulthood, when the child graduates from a pediatric practice. The most common reasons noted for not treating special needs patients by general dentists were the level of the patient's disease; the patient's (disruptive) behavior; and the dentist's lack of sufficient training or experience. ${ }^{13-16}$ Low insurance reimbursement from state insurance has also been cited as a factor in providers not participating in Medicaid. ${ }^{17}$ Many children with ASD have unmet dental needs, but are on state insurance, which is an important barrier to receive care, especially in rural areas. ${ }^{18,19}$
1Department of Pediatric Dentistry, Kids Care Dental and Orthodontics,
Cupertino, California, USA
2Department of Behavioral Sciences and Community Health, UConn
Health, Psychiatry, Farmington, Connecticut, USA
Corresponding Author: Nidhi Taneja, Department of Pediatric
Dentistry, Kids Care Dental and Orthodontics, Cupertino, USA, e-mail:
ntaneja.dds@gmail.com
How to cite this article: Taneja N, Litt MD. Barriers for Dentists in
Treating Children with Autism Spectrum Disorders. J South Asian
Assoc Pediatr Dent 2020;3(2):65-69.
Source of support: Nil
Conflict of interest: None

In addition to the issue of payment is the problem of training. The pediatric dentistry community has yet to publish any practice guidelines or standardized tools or procedures to manage children with autism in the dental office. It is suspected that some providers may decline to treat an ASD child in part due to a lack of knowledge regarding behavioral management. As reported in previous studies, other barriers to provide care (as perceived by the practitioners) include perceived lack of motivation of caretakers and lack of experience and training in managing this population. ${ }^{13,14,16}$

Patients who have an ASD diagnosis do not necessarily differ from other patients in terms of their dental presentations and problems. What differs is the flow of these patients through the dental office, and the management techniques that are employed to have a successful visit with regard to behavior management and communication. The purpose of this study was to explore the barriers perceived by dentists to provide dental care to children with ASD. Answers to these questions would help us develop an understanding of the educational and logistical barriers faced by 
dentists in providing care for children with autism. It is hoped that highlighting these issues will help eventually to improve access to dental care for ASD children. By establishing care for children with ASD early on, many aspects of care like prevention of oral disease and improved behavioral management for children with ASD can be achieved.

\section{Materials and Methods \\ Participants}

This survey sample consisted of 109 general dentists ( 67 men and 42 women) who completed a questionnaire during their attendance at a national dental conference. The respondents varied in experience in treating children with ASD and in the number of children with ASD treated in their practices. Additional details regarding the sample of dentists appear in the Results section. Questionnaires completed by dental specialists and incomplete surveys were excluded from data analysis.

\section{Survey}

In the absence of an existing questionnaire regarding barriers perceived by dentists, the survey in the present study was constructed based on barriers reported in the literature. ${ }^{13,14,16,20}$ The questionnaire was piloted and validated at the University of Connecticut School of Dental Medicine using a sample of pediatric dentistry residents, and prepared for distribution. Survey items included demographics, practice type, type of insurance accepted, and setting in which training in ASD management, if any, was received. Perceived barriers to provide care to ASD children were assessed with 10 items. Potential barriers assessed were: (1) Do not get these patients in my practice; (2) ASD children are uncooperative; (3) Lack of sufficient training to manage these children; (4) Lack of practice guidelines to manage children with ASD; (5) Lack of reimbursement for behavior management; (6) Behavior management/treatment preparations take too long; (7) Do not want to manage complex medical problems associated with ASD; (8) Do not accept State insurance; (9) Caregivers of ASD children are not reliable; and (10) Office staff is not trained. For each potential barrier listed, dentists indicated whether they disagreed it was a barrier to provide care (scored -1$)$, were neutral (scored 0 ), or agreed it was a barrier (scored +1 ).

\section{Procedures}

This research was approved by the Institutional Review Board at University of Connecticut Health Center. This study was conducted at the Yankee Dental Congress at the Boston, Massachusetts, Convention and Exhibit Center in January 2017. Surveys and consent forms were distributed to interested respondents at the Congress, and collected directly by a research volunteer. The same questionnaire was administered both to those who reported treating children with ASD and those who reported that they did not.

The data collected through the completed surveys were entered into an SPSS system file for analysis and evaluation. The dependent variables were two scores derived from the barrier items in the survey. The first was the total agreement score calculated by summing the scores of agreements ( -1 to 1 ) for each of the 10 items (with a total agreement score ranging from -10 to +10 ). The second score was simply the number of barriers that was endorsed as a problem (i.e., scored +1 ) by dentists (with counts ranging from 0 to 10). The independent variables were dentist's demographics, dentist's self-reported experience in treating children with ASD in practice, and type of dental insurance accepted by the dentist's office. In addition to examine responses from all dentists, the reported barriers were further explored for dentists in the two groups: Those reporting they treated children with ASD and those who reported they did not.

Between-group $t$-tests were conducted to evaluate the difference between treating and non-treating dentists on the two summary scores: Total barriers agreements score and total number of items endorsed as barriers. In addition, agreement ratings for each item were examined by ASD treating group, using Chi-square analyses.

\section{Results}

Dentists in this study had a mean of 15 years' experience in the practice of dentistry. Of these, $74 \%$ of the dentists reported treating children with ASD, but also reported that they treated fewer than three patients with ASD per month. Most of the children treated by this sample were mildly or moderately severe on the autism spectrum. Table 1 shows the characteristics of all the dentists surveyed, grouped by whether they reported treating children with ASD or not.

On average, the entire sample of dentists endorsed 3.25 of the 10 items as barriers to provide care to children with ASD. Their total perceived barrier score was 0.3 on the -10 to 10 scale, suggesting that these dentists did not perceive these potential barriers as especially important in their decisions to treat children with ASD. The group of dentists was further divided based on whether they treated patients with ASD or not. Table 2 shows how the two groups compared on the two computed barriers scores. As seen in the table, the mean of the total perceived barriers score for the two groups of dentists was significantly higher for those who did not see these children in practice. On the contrary, the mean number of barriers endorsed by the dentists treating children with ASD was not statistically different from the number identified by those not treating ASD children. That is, on balance, those who did not treat ASD children were more likely to perceive barriers to provide treatment to ASD children than did those who routinely treated these children.

Figure 1 shows the proportion of dentists overall who endorsed each item as a barrier to provide treatment or not. As seen in the figure, fewer than a quarter of the dentists in the present study reported lack of training to be a barrier in providing treatment to children with ASD. Over $50 \%$ of the total sample, however, indicated that lack of treatment guidelines was a barrier to provide care. Lack of reimbursement and time for behavior management preparation were also cited by many as barriers.

Figure 2 shows the degree of agreement or disagreement as to whether a particular item was a barrier to provide treatment, separated by treating vs non-treating subgroups. As indicated in the figure, a significantly higher number of the dentists who were not treating children with ASD felt that insufficient training in ASD management was a barrier $\left(\chi^{2}=4.40 ; p<0.05\right)$. Those not treating ASD children were also more likely to see a lack of training on the part of their staff to be a barrier to provide care $\left(\chi^{2}=4.58 ; p<\right.$ $0.05)$. On the contrary, those who did treat ASD children were more likely than non-treating dentists to agree that reimbursement was a barrier to care $\left(\chi^{2}=5.91 ; p<0.05\right)$, and that caregivers could be unreliable $\left(\chi^{2}=5.41 ; p<0.05\right)$.

Only a quarter of the dentists from both the groups felt that the behavioral cooperation of ASD children was a barrier to provide treatment, and the between-group result was not statistically 
Table 1: Characteristics of general dentists surveyed $(n=109)$

\begin{tabular}{|c|c|c|c|c|}
\hline & & \multicolumn{2}{|c|}{ Treat ASD } & \multirow[b]{2}{*}{ All dentists $(n=109)$} \\
\hline & & No $(n=28)(25.7 \%)$ & Yes $(n=81)(74.3 \%)$ & \\
\hline \multirow[t]{2}{*}{ Dentist gender (\#, \% of sample) } & Male & $19(67.9)$ & $48(59.3)$ & $67(61.5)$ \\
\hline & Female & $9(32.1)$ & $33(40.7)$ & $42(38.5)$ \\
\hline Years in practice (mean, SD) & $13.5(11.5)$ & $16.3(12.1)$ & $15.6(11.95)$ & \\
\hline ASD pts treated/month (mean, SD) & & $2.79(4.2)$ & & \\
\hline \multirow[t]{3}{*}{ Type of ASD treated (\#, \% of sample) } & Mild only & & $38(46.9)$ & \\
\hline & Mild-moderate & & $36(44.4)$ & \\
\hline & All severity & & $7(8.6)$ & \\
\hline \multirow[t]{3}{*}{ Type of insurance accepted (\#, \% of sample) } & Public & $1(4.5)$ & $14(17.3)$ & $15(14.6)$ \\
\hline & Private & $12(54.5)$ & $27(33.3)$ & 39 (37.9) \\
\hline & Both & $9(40.9)$ & $40(49.4)$ & $49(47.6)$ \\
\hline \multirow{5}{*}{$\begin{array}{l}\text { Training source for ASD management (\#, \% of } \\
\text { sample) }{ }^{\text {a }}\end{array}$} & Experience in practice & $6(30)$ & $58(72.5)$ & $64(58.7)$ \\
\hline & Dental school & $9(45)$ & $22(27.2)$ & $31(28.4)$ \\
\hline & Residency/fellowship & $6(30)$ & $22(27.2)$ & $28(25.6)$ \\
\hline & CME & $3(15)$ & $6(7.4)$ & $9(8.3)$ \\
\hline & Others & $3(15)$ & $4(4.9)$ & $7(6.4)$ \\
\hline
\end{tabular}

apercentages may exceed $100 \%$ due to multiple responses allowed

Table 2: Summary of between-groups tests of barriers to provide care to ASD children as perceived by general dentists. General dentists who report treating those with ASD vs those who do not

\begin{tabular}{|c|c|c|c|c|c|}
\hline Barrier score & $\begin{array}{l}\text { Do not treat ASD } \\
(n=28)(25.7 \%)\end{array}$ & $\begin{array}{l}\text { Do treat ASD } \\
(n=81)(74.3 \%)\end{array}$ & $\begin{array}{l}t \text { (between-groups) } \\
(d f=107)\end{array}$ & $p$ value & $\begin{array}{l}\text { All general dentists } \\
(n=109)\end{array}$ \\
\hline $\begin{array}{l}\text { Total perceived barriers } \\
\text { score }(M, S D)^{\mathrm{a}}\end{array}$ & $2.14(3.5)$ & $-0.22(4.1)$ & 2.72 & 0.008 & $0.30(4.1)$ \\
\hline $\begin{array}{l}\text { No. of barriers endorsed } \\
(M, S D)^{b}\end{array}$ & $3.14(2.5)$ & $3.28(2.2)$ & -0.28 & 0.780 & $3.25(2.3)$ \\
\hline
\end{tabular}

${ }^{\mathrm{a} S c o r e s ~ r a n g e ~ f r o m ~-10 ~(d i s a g r e e m e n t ~ t h a t ~ i t e m s ~ r e p r e s e n t ~ b a r r i e r s) ~ t o ~} 10$ (agreement that items are barriers)

${ }^{\mathrm{b}}$ Number of items endorsed as barriers ranges from 0 to 10

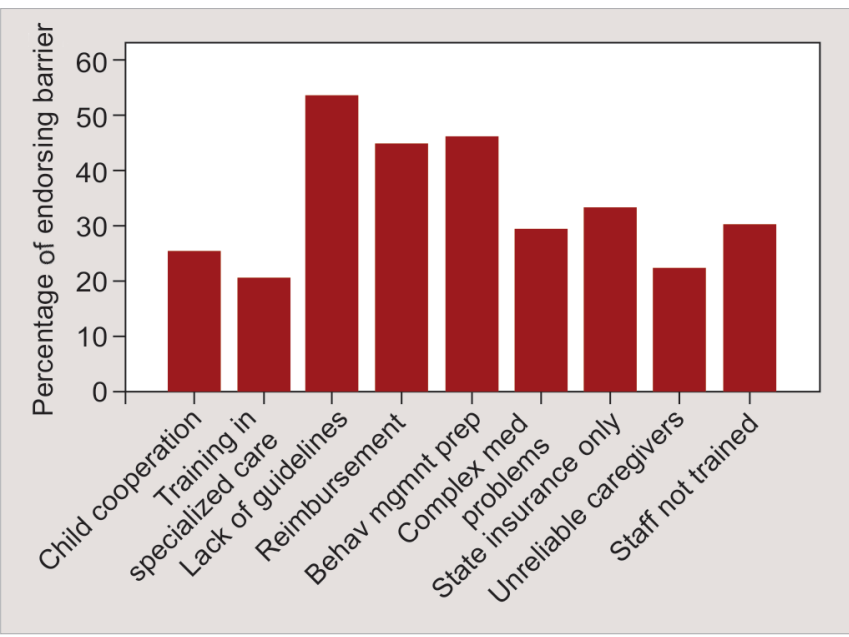

Fig. 1: Barriers to all general dentists

significant. Lack of practice guidelines for treating children with ASD was the most common barrier endorsed by the dentists overall, with no difference between groups.

\section{Discussion}

Going to a dentist involves non-routine social interactions, oral sensory stimulations, and cooperative communication. The dental office is a hyper-stimulated environment with bright overhead light, loud noises from the use of dental instruments, oral sensory stimulation, etc. This could lead to a sensory overload for a child with ASD, which may go unnoticed if a dentist is not aware of these symptoms. These patients often require special behavioral management strategies (e.g., desensitization, frequent, and consistent visits) to allow them to have a successful dental visit. ${ }^{21}$ Studies show that patients with ASD were the least preferred among various other conditions to be treated by general dentists in their practice. ${ }^{22,23}$ Caregivers of children with ASD have been reported to have difficulty in finding a dentist who is comfortable in treating their children with ASD. ${ }^{24}$ In the present study, $26 \%$ of the general dentists reported not treating any patients with ASD, while $74 \%$ reported treating these children some of the time. This is quite a high proportion of dentists who treat children with ASD, and a much higher proportion than that reported by general dentists in the state of Michigan, where only $32 \%$ of the dentists reported treating patients with ASD. ${ }^{14}$ 


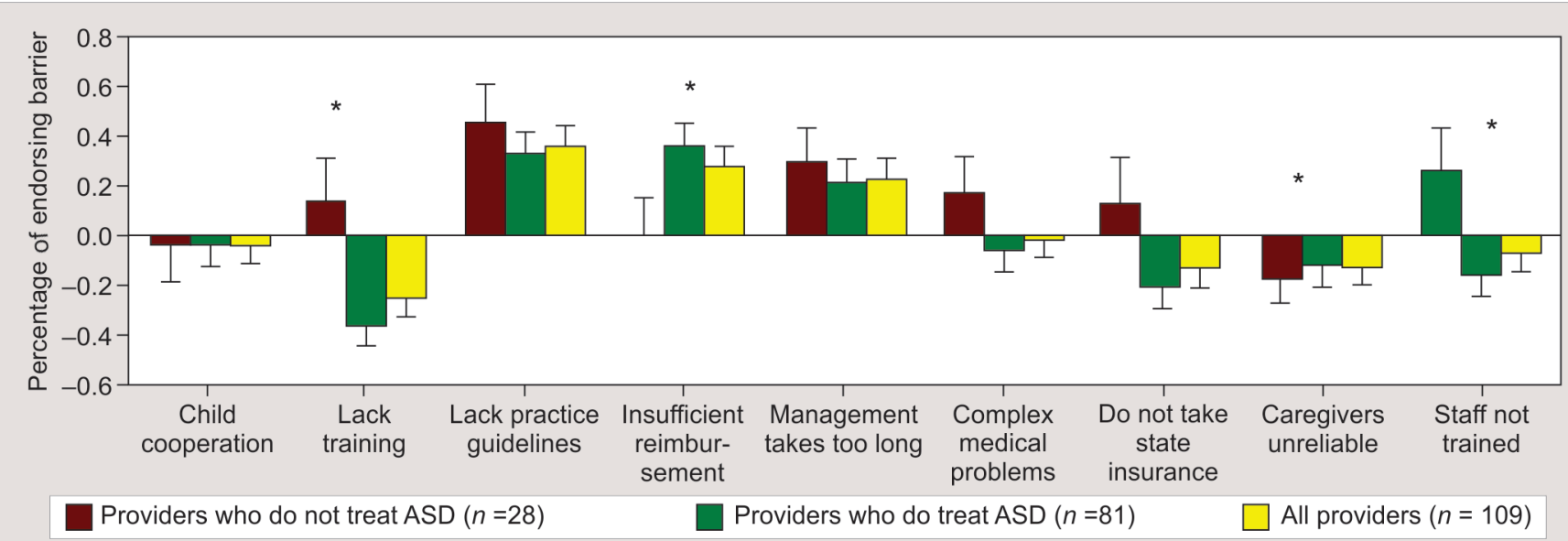

Fig. 2: Average barrier agreement score per item for providers who do not treat children with ASD, those who do treat ASD children, and the entire sample. Scores for each item were -1 (not a barrier), 0 (neutral), or 1 (definitely a barrier to provide treatment). Stars $\left({ }^{*}\right)$ denotes those items on which providers who did or did not treat ASD children differed significantly

The present study found that the average number of barriers endorsed by dentists who reported treating children with ASD was only marginally more than that reported by the group of dentists who do not see patients with ASD. Though this was not a statistically significant result, the study did identify some unique barriers, which were explored further. The minimal difference in the scores of the two groups can be attributed to two factors. First, the dentists in the present study treated fewer than three children with ASD per month, which is relatively low in terms of dentist's exposure to the ASD population. Second, in the present study, almost $90 \%$ of the general dentists saw mild-moderate severity patients with ASD, who tend to require less behavioral management than severely autistic children. Thus, for these dentists, the general perception may have been that treating ASD children was not particularly challenging, and thus the dentists may perceive few barriers to treat these children.

Poor reimbursement to providers can be a significant barrier to care for ASD children. Children with ASD often require modifications in behavior management techniques and often require more time for their treatment. Low insurance reimbursement rates for special care have driven some dental providers out of state insurance plans. ${ }^{25}$ In the present study, more than three-quarters of the children with ASD (78.3\%) were covered solely by a public/state insurance. More than half of the dentists who did not treat patients with ASD accepted only private insurance in their practice, and the lack of acceptable insurance was cited as a barrier to provide care by $43.5 \%$ of the dentists who did treat children with ASD vs $30 \%$ for those who did see ASD patients. If insurance companies do not reimburse dentists sufficiently for their time and expertise, they will have little incentive to spend time in desensitizing these children or seeing them multiple times in their practice. This is reflected by the finding here: More than half of all respondents acknowledged that lack of sufficient reimbursement for behavior management for ASD patients was a barrier to treatment.

One important barrier as perceived by the practitioners in previous studies was a perceived lack of training. ${ }^{14-16,20}$ In the present study, $36.4 \%$ of the dentists who reported not treating patients with ASD agreed that insufficient training in this field was a barrier for them in providing care to this population. A majority of dentists reported that their experience in treating these children was limited to what they had learned during their clinical practice. Training in caring for special needs patients seems to be inadequate in dental students. ${ }^{26}$ The quality of pediatric dentists' educational experiences correlates with the frequency of appropriate behavior management strategies used while treating patients with ASD. ${ }^{14}$

Though many patients with severe autism are referred to a hospital setting for their behavior and/or medical management, there are many patients on the spectrum who are cooperative enough that they can be treated in dental offices on a regular basis for preventative care. As these families already face enormous emotional and financial challenges, allowing for early intervention and preventative care for these more cooperative patients can have a significant impact on the overall health and well-being of these patients and families. Thus, providing training in the treatment of developmentally disabled children in dental school and general practice residency could go a long way toward improving access to care for ASD children.

One way to increase the number of dentists who will provide care to ASD children is through establishing a set of practice guidelines. In this study, $54.4 \%$ dentists feel constrained by lack of guidance in treating children with ASD. There are no published guidelines from the American Academy of Pediatric Dentistry (AAPD) or the American Dental Association (ADA) establishing gold standard techniques on this topic. Efforts to establish standard guidelines and research in the area of testing various behavioral strategies for ASD patients in the dental setting would be an important step toward improving care for this population.

\section{CONCLUSION}

The commonly endorsed barriers for general dentists in treating children with ASD were the lack of available guidelines, the lack of sufficient reimbursement for behavior management of ASD children, and perceived difficulty or time required in managing the child's behavior. Interestingly, most dentists did not perceive lack of training as a barrier to provide care for these children. Overall, they did not endorse many items as particular barriers to provide care to this population. It is important for dental healthcare providers 
to be familiar with ASD and its associated clinical manifestation so that they adapt to their patients' individual needs and use the appropriate behavior management strategies to gain maximum cooperation.

\section{References}

1. Carter AS. Social development in autism. In: Volkmar FR, Paul R, Klin A, et al. ed. Handbook of autism and pervasive developmental disorders: Diagnosis, development, neurobiology, and behavior. Hoboken, NJ, US: John Wiley \& Sons Inc; 2005. pp. 312-334.

2. Tantam $D$. The challenge of adolescents and adults with Asperger syndrome. Child Adolesc Psychiatr Clin N Am 2003;12(1):143-163. DOI: 10.1016/S1056-4993(02)00053-6.

3. Weil TN, Inglehart MR. Three- to 21-year-old patients with autism spectrum disorders: parents' perceptions of severity of symptoms, oral health, and oral health-related behavior. Pediatr Dent 2012;34(7):473-479.

4. Blaxill MF. What's going on? The question of time trends in autism. Public Health Rep 2004;119(6):536-551. DOI: 10.1016/ j.phr.2004.09.003.

5. Weintraub K. The prevalence puzzle: autism counts. Nature 2011;479(7371):22-24. DOI: 10.1038/479022a.

6. Marshall J, Sheller B, Mancl L. Caries-risk assessment and caries status of children with autism. Pediatr Dent 2010;32(1):69-75.

7. Nelson LP, Getzin A, Graham D, et al. Unmet dental needs and barriers to care for children with significant special health care needs. Pediatr Dent 2011;33(1):29-36.

8. Lai B, Milano M, Roberts MW, et al. Unmet dental needs and barriers to dental care among children with autism spectrum disorders. J Autism Dev Disord 2012;42(7):1294-1303. DOI: 10.1007/s10803-0111362-2.

9. Limeres-Posse J, Castano-Novoa P, Abeleira-Pazos M, et al. Behavioral aspects of patients with autism spectrum disorders (ASD) that affect their dental management. Med Oral Patol Oral Cir Bucal 2014;19(5):e467-e472. DOI: 10.4317/medoral.19566.

10. Brickhouse TH, Farrington FH, Best AM, et al. Barriers to dental care for children in Virginia with autism spectrum disorders. J Dent Child (Chic) 2009;76(3):188-193.

11. Barry S, O'Sullivan EA, Toumba KJ. Barriers to dental care for children with autism spectrum disorder. Eur Arch Paediatr Dent 2014;15(2): 127-134. DOI: 10.1007/s40368-013-0075-y.

12. Wiener RC, Vohra R, Sambamoorthi U, et al. Caregiver burdens and preventive dental care for children with autism spectrum disorder, developmental disability and/or mental health conditions: national survey of CSHCN, 2009-2010. Matern Child Health J 2016;20(12): 2573-2580. DOI: 10.1007/s10995-016-2083-0.
13. Adyanthaya A, Sreelakshmi N, Ismail S, et al. Barriers to dental care for children with special needs: general dentists' perception in Kerala, India. J Indian Soc Pedod Prev Dent 2017;35(3):216-222. DOI: 10.4103/ JISPPD.JISPPD_152_16.

14. Weil TN, Inglehart MR. Dental education and dentists' attitudes and behavior concerning patients with autism. J Dent Educ 2010;74(12):1294-1307. DOI: 10.1002/j.0022-0337.2010.74.12. tb05005.x.

15. Casamassimo PS, Seale NS, Ruehs K. General dentists' perceptions of educational and treatment issues affecting access to care for children with special health care needs. J Dent Educ 2004;68(1):23-28. DOI: 10.1002/j.0022-0337.2004.68.1.tb03730.x.

16. Salama FS, Kebriaei A, Durham T. Oral care for special needs patients: a survey of Nebraska general dentists. Pediatr Dent 2011;33(5):409-414.

17. Logan $\mathrm{HL}$, Catalanotto F, Guo $\mathrm{Y}$, et al. Barriers to medicaid participation among Florida dentists. J Health Care Poor Underserved 2015;26(1):154-167. DOI: 10.1353/hpu.2015.0000.

18. Chiri G, Warfield ME. Unmet need and problems accessing core health care services for children with autism spectrum disorder. Matern Child Health J 2012;16(5):1081-1091. DOI: 10.1007/s10995-011-0833-6.

19. Chi DL, Momany ET, Mancl LA, et al. Dental homes for children with autism: a longitudinal analysis of lowa medicaid's I-smile program. Am J Prev Med 2016;50(5):609-615. DOI: 10.1016/j.amepre.2015.08.022.

20. Dao LP, Zwetchkenbaum S, Inglehart MR. General dentists and special needs patients: does dental education matter? J Dent Educ 2005;69(10):1107-1115. DOI: 10.1002/j.0022-0337.2005.69.10. tb04011.x.

21. Czornobay LFM, Munhoz EA, Lisboa ML, et al. Autism spectrum disorder: Review of literature and dental management. World J Stomatol 2018;6(2):6-18. DOI: 10.5321/wjs.v6.i2.11.

22. Manning-Courtney P. Addressing the crisis in access to autism treatment using health care improvement science. Arch Pediatr Adolesc Med 2007;161(4):414-415. DOI: 10.1001/archpedi.161.4.414.

23. Liptak GS, Benzoni LB, Mruzek DW, et al. Disparities in diagnosis and access to health services for children with autism: data from the national survey of children's health. J Dev Behav Pediatr 2008;29(3):152-160. DOI: 10.1097/DBP.0b013e318165c7a0.

24. Taneja N, Litt M. Caregivers' barriers to dental care for children with autism spectrum disorder. J Dent Child 2020;87(2):98-102.

25. Sarkar $M$, et al. Differences in health care needs, health care utilization, and health care outcomes among children with special health care needs in Ohio: a comparative analysis between medicaid and private insurance. J Public Health Manag Pract 2017;23(1):e1-e9. DOI: 10.1097/ PHH.0000000000000403.

26. Vainio L, Krause M, Inglehart MR. Patients with special needs: dental students' educational experiences, attitudes, and behavior. J Dent Educ 2011;75(1):13-22. DOI: 10.1002/j.0022-0337.2011.75.1.tb05018.x. 